$100^{\circ}$, finely powdered, and allowed to come into equilibrium with the moisture of the air and weighed. Half-gram samples of this are used for the estimation of the SH sulphur.

\title{
Summary.
}

Distribution of Stiphur in Per Cent. of Total Sulphur in Brains at Different AGESS.

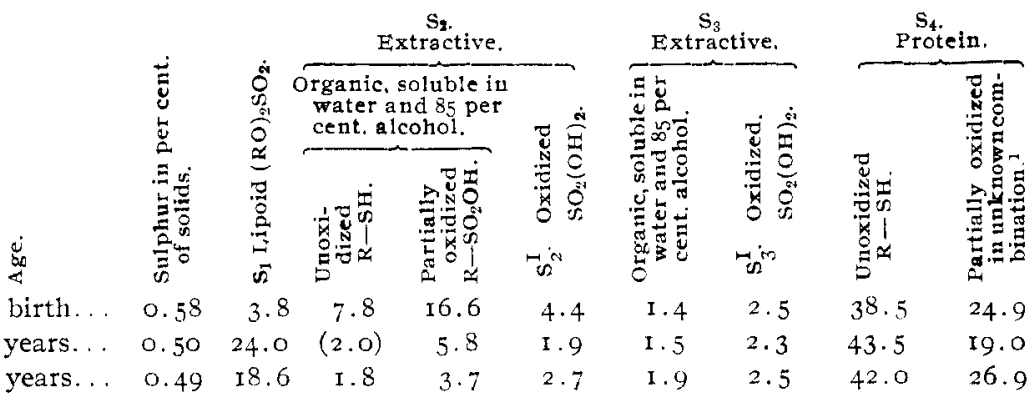

The Variation in the total sulphur is not very great. The greatest variations are: An increase in the lipoid sulphur with age, which later again decreases. A decrease in the water-soluble organic sulphur with age. The presence of $\mathrm{SH}$ sulphur among the group of extractives is of especial interest and will be taken up more in detail in a later paper. The physiological interpretation of these results will be reserved until more data can be collected.

The methods here outlined are then capable of detecting differences in the same tissue at different ages, or in different states of physiological activity (growth).

[From the Dept. of Agr. Chemistry of the University of Wisconsin.]

\section{THE QUANTITATIVE ESTIMATION OF LACTIC ACID IN CHEESE.}

BY S. SUZUKII AND E. B. HART.

Received October 9 , Igog.

In connection with, chemical studies of cheese ripening that are being conducted at the Wisconsin Experiment Station, in co-operation with the Dairy Division of the Bureau of Animal Industry, United States Department of Agriculture, it has been necessary to employ some quantitative method for the estimation of lactic acid. In order to fix upon the most reliable method for this work, preliminary examination of the accuracy and applicability of several methods already proposed was undertaken.

By difference.

${ }^{2}$ Expert in dairy chemistry, Dairy Division, United States Department of Agriculture. Engaged in co-operative work between the Division and the Station. 
Palm Method.-R. Palm ${ }^{1}$ in $\mathbf{1} 883$ found that basic lead lactate, which corresponds to the formula $3 \mathrm{PbO}_{2} \mathrm{C}_{3} \mathrm{H}_{8} \mathrm{O}_{3}$, is formed when ammoniacal alcohol is added in excess to a solution of lactic acid and basir lead acetate. In $1887^{2}$ Palm proposed this reaction as the basis for his quantitative method. This method has since been used by Van Slyke and Bosworth ${ }^{3}$ and while they did not consider it altogether satisfactory, conciuded that it appeared to be the most efficient one available. Its relative simplicity and rapidity as compared with the zinc-lactate method led us to a study of its accuracy.

For this purpose, inactive lactic acid was used and the description of its estimation as given by Palm rigidly followed.

Analysis of the lead precipitate, by careful ignition in a porcelain crucible with a few drops of nitric acid, gave lead oxide corresponding to 78.7 and 78.4 per cent. of $\mathrm{PbO}$. Calculated for $3 \mathrm{PbO} .2 \mathrm{C}_{3} \mathrm{H}_{8} \mathrm{O}_{3}: \mathrm{PbO}=78.5$ per cent.

These results establish the fact that lactic acid forms a definite chemical compound, ${ }_{3} \mathrm{PbO} .2 \mathrm{C}_{3} \mathrm{H}_{6} \mathrm{O}_{3}$, with basic lead acetate in an ammoniacal alcohol solution. The quantitative determinations by this method gave the following results:

I. 0.44 I gram of inactive lactic acid ${ }^{4}$ gave a recovery of 0.345 gram of the same acid, or 78.2 per cent. ${ }^{5}$

These results are in agreement with those obtained by Dobriner, ${ }^{6}$ who likewise was unable to secure quantitative results with the Palm method.

Partheil Method.-This rapid method was recommended in 1902 by Partheil. ${ }^{7}$ It is based upon the observation that with superheated steam at a high temperature, vaporization of lactic acid takes place. The process, in brief, is as follows:

Ten cc. of the solution containing lactic acid are placed in a distilling flask and the apparatus properly connected to a condenser and receiver. The distilling flask is placed in an air bath, which is maintained at $1 \mathrm{IO}^{\circ}$. Through the lactic acid, superheated steam is now passed and the distillation continued until $300-400 \mathrm{cc}$. are collected. The distillate is boiled with an excess and known amount of normal potassium hydroxide solution and titrated back with normal sulphuric acid. This affords the data for the estimation of the amount of lactic acid present. In our experiments Io cc. of lactic acid solution, corresponding to I I $9 \mathrm{cc}$.

$1 Z$. anal. Chem., 22, 223 (1883).

${ }^{2}$ Ibid., 26, 33 (I 887 ).

3 Technical Bulletin, No. 4, N. Y. Agr. Exp. Sta.

- It was shown by retitration of the boiled alkaline solution of the lactates that the lactic acid used was practically free from anhydride.

- Under similar conditions from 0.265 gram of the acid 0.208 gram or 78.4 per cent. was recovered.

- Z. anal. Chem., 38, 58 (1899).

7 Z. untersuch. 0. Nahrungs u. Genussmittel, 5, 1056 (1902). 
of an O.I $N$ solution, were used. The results are given in the following table:

Table showing the results with the Partheil method.

\begin{tabular}{|c|c|c|c|c|c|}
\hline & \multicolumn{2}{|c|}{ Temperature. } & \multirow{2}{*}{$\begin{array}{l}\text { Distillate } \\
\text { in cc. }\end{array}$} & \multirow{2}{*}{$\begin{array}{l}\text { The acidity } \\
\text { of distillate } \\
\text { in o.I } N \text { cc. }\end{array}$} & \multirow{2}{*}{$\begin{array}{l}\text { Acid } \\
\text { distilled, } \\
\text { per cent. }\end{array}$} \\
\hline & In air bath. & In flask. & & & \\
\hline I . . . . & $110-115^{\circ}$ & $104-108^{\circ}$ & 750 & 24.25 & 20.38 \\
\hline $\mathrm{II}^{1} \ldots$ & $120^{\circ}$ & $108-109^{\circ}$ & 750 & 39.50 & 33.20 \\
\hline III . . & $\pm 30^{\circ}$ & $120^{\circ}$ & 750 & I 55.00 & 96.60 \\
\hline IV $\ldots \ldots$ & $120-130^{\circ}$ & $120^{\circ}$ & 1000 & II 5.00 & 96.60 \\
\hline$V \ldots \ldots$ & I $30^{\circ}$ & $130^{\circ}$ & 750 & 117.50 & 98.80 \\
\hline
\end{tabular}

In view of the possibility that lactic acid, subjected to such a high temperature as $130^{\circ}$ might be decomposed, a portion of the distillate in Experiment $\mathrm{V}$ was used for its identification. This was done by preparing the zinc salt. 1.522 grams of this crystalline zinc lactate gave 0.263 gram of water of crystallization, which corresponds to 17.28 per cent. The theoretical amount is 18 . I 8 per cent.

The above experiments show clearly that free inactive lactic acid can be distilled at $130^{\circ}$ without decomposition, but that the distillation is incomplete when the temperature of the steam falls below $130^{\circ}$.

The amount of distillate should be at least $750 \mathrm{cc}$. All attempts to distil lactic acid under reduced pressure failed.

To make the method applicable to our work, it was necessary to determine whether in the presence of non-volatile organic acids, lactic acid could be quantitatively separated. To determine this, a mixture was prepared consisting of 0.67 gram of malic acid, 0.75 gram of tartaric acid, 0.59 gram of succinic acid, 0.70 gram of citric acid, and 0.63 gram of oxalic acid. A solution of these was subjected to distillation with steam at $101-103^{\circ}$, with the temperature of the air bath at $130^{\circ}$. Five hundred $\mathrm{cc}$. of the distillate gave an acidity equivalent to II.3 cc. of an o.I $N$ solution. It is apparent from this experiment that the method is inapplicable to a mixture of lactic acid and the above organic acids, and consequently to cheese analysis.

Zinc Lactate Method.-This method involves the complete extraction of the acidified material with ether, removal of the solvent, and preparation of the zinc salt of lactic acid. The identification of the form and purity is dependent upon the amount of water of crystallization.

To determine its applicability to cheese analysis the following experiment was carried out:

I.Or4 grams of crystalline calcium lactate were mixed with roo grams of cheese, which had been previously acidified and thoroughly extracted with ether. The calcium lactate used had 29.I per cent. water of crys-

${ }^{1}$ Four grams of sodium sulphate were added to the lactic acid solution in order to raise the temperature inside of the flask and to accelerate the vaporization of lactic acid. 
tallization, while the theoretical amount is 29.2 per cent. The mixture of cheese and calcium lactate was strongly acidified with dilute sulphuric acid and extracted 24 times with 50-I5O cc. portions of ether. The ether was removed from the united extracts, baryta water added in excess, and the solution boiled for a few minutes. The mixture was then neutralized with dilute sulphuric acid and the barium sulphate removed. The filtrate was next treated with a solution of zinc sulphate, care being taken to avoid an excess. The barium sulphate precipitate formed at this point was separated by filtration. On evaporating the filtrate to a small volume, the zinc lactate began to crystallize out. The solution was then placed in a desiccator and after a few days the crystals were filtered out and washed with a small volume of cold water. The mother liquor and washings were treated in a similar way and a second and third yield of crystals obtained.

0.965 gram of crystalline zinc lactate was collected and gave 0.174 gram of water of crystallization, equivalent to 18.0 per cent. The theoretical quantity of water of crystallization for the zinc salt of inactive lactic acid is 18.18 per cent.

0.965 gram of inactive zinc lactate is equivalent to 0.584 gram of lactic acid; I.OI4 grams of crystalline calcium lactate, the initial amount used in this experiment is equivalent to 0.593 gram of lactic acid. This experiment represents a recovery of 98.4 per cent. of the total lactic acid used. This result is probably a maximum, in view of the fact that one part of the zinc salt of inactive lactic acid is soluble in 53 parts of water at $15^{\circ}$. However, by the use of a minimum quantity of cold wash water and by careful manipulation, the method can be made quantitative.

\section{Summary.}

I. The basic lead salt of inactive lactic acid is a definite chemical compound, with the formula of $3{ }_{3} \mathrm{PbO} .2 \mathrm{C}_{3} \mathrm{H}_{6} \mathrm{O}_{3}$.

2. The Palm method, based on the formation of the above compound, gave low results and could not be used as a quantitative method for the estimation of lactic acid in cheese.

3. The Partheil method of distillation, when applied to inactive lactic acid, must be done with superheated steam at a temperature of $130^{\circ}$ and the distillation continued until $750 \mathrm{cc}$. have been collected.

4. Inactive lactic acid is not decomposed when distilled at $130^{\circ}$.

5. The Partheil method is not applicable to the quantitative separation of lactic acid from a mixture in which may occur such acids as malic, citric, tartaric, oxalic, and succinic.

6. In cheese analysis, the usual method of lactic acid estimation-extraction with ether after acidifying and separation of the zinc salt gave fairly satisfactory results when carefully manipulated. 